\title{
Parâmetros Genéticos para Produções de Leite e Gordura nas Três Primeiras Lactações de Vacas Holandesas
}

\section{Ary Ferreira de Freitas ${ }^{1,2}$, Marcus Cordeiro Durães ${ }^{1,2}$, José Valente ${ }^{1,2}$, Nilson Milagres Teixeira ${ }^{1,2}$, Mário Luiz Martinez ${ }^{1,2}$, Márcio Nery Magalhães Junior ${ }^{3}$}

\begin{abstract}
RESUMO - Foram analisadas 9527 lactações de vacas puras de origem (PO) da raça Holandesa, iniciadas entre 1988 e 1997, em rebanhos no Estado de Minas Gerais. Estabeleceram-se dois conjuntos de dados: um com as vacas de primeira lactação (Conjunto I) e outro com as vacas de primeira até a terceira lactação (Conjunto II). Para as análises das produções de leite e gordura até 305 dias, adotaramse modelos mistos com a metodologia da máxima verossimilhança restrita (REML). As médias para produções de leite e gordura, até 305 dias de lactação, foram $5870 \pm 1662 \mathrm{~kg}$ e $199 \pm 55 \mathrm{~kg}$, respectivamente, para o conjunto I. Para o conjunto II, essas médias, na mesma ordem, foram $5521 \pm 1523 \mathrm{~kg}$ e $187 \pm 50 \mathrm{~kg}$, na primeira lactação; $6421 \pm 1789 \mathrm{~kg}$ e $215 \pm 58 \mathrm{~kg}$, na segunda lactação e $7045 \pm 1903$ $\mathrm{kg}$ e $231 \pm 60 \mathrm{~kg}$, na terceira lactação. As estimativas de herdabilidade para produções de leite e gordura foram $0,28 \pm 0,04$ e $0,20 \pm 0,03$, respectivamente, para o conjunto I. Para o conjunto II, foram $0,16 \pm 0,09$ e $0,09 \pm 0,09$, na primeira; $0,17 \pm 0,11$ e $0,20 \pm 0,11$ na segunda e $0,16 \pm 0,10$ e $0,10 \pm 0,16$ na terceira lactação, para produções de leite e gordura, respectivamente. As correlações genéticas entre as características estudadas foram altas, variando de 0,86 a 1,00 .
\end{abstract}

Palavras-chave: parâmetros genéticos, produção de gordura, produção de leite

\section{Genetic Parameters of Milk and Fat Yields of Holstein Cows in the Three First Lactations}

ABSTRACT - In this study 9,527 lactations of purebreed Holstein cows, calved between 1988 to 1997, from herds in the Minas Gerais State, were analysed. Two data sets were established: one with first lactations only and another with the first lactation until the third one. Milk and fat 305-day yields were analysed using a multivariate mixed model and restricted maximum likelihood procedure (REML). The milk and fat 305 days yields averages were respectively 5,870 $\pm 1,662 \mathrm{~kg}$ and $199 \pm 55 \mathrm{~kg}$ for set I and 5,521 $\pm 1,523 \mathrm{~kg}$ and $187 \pm 50 \mathrm{~kg}$ for set II in the first lactation, and $6,421 \pm 1,789 \mathrm{~kg}$ and $215 \pm 58 \mathrm{~kg}$ for the second lactation, and 7,045 $\pm 1,903 \mathrm{~kg}$ and $231 \pm 60 \mathrm{~kg}$ for the third lactation, respectively. Heritabilities estimated for milk and fat yields in set I (first lactation) were $.28 \pm .04$ and $.20 \pm .03$ and using the set II, were $.16 \pm .09$ e $.9 \pm .9$ for milk and fat yields in the first lactation, $.17 \pm .11$ and $.20 \pm .11$ for second one, and $.16 \pm .10$ and $.10 \pm .16$ in third lactation, respectively. Genetic correlations were high and ranged from .86 to 1.0 .

Key Words: fat yield, genetic parameters, milk yield

\section{Introdução}

Avaliações genéticas de vacas e touros, em que se usa somente a primeira lactação, têm sido normalmente adotadas, apesar de os registros de outras lactações da vaca contribuírem para melhorar a precisão nas estimativas dos parâmetros genéticos. Assume-se que o primeiro registro de produção de uma vaca é um bom indicador do desempenho total na sua vida produtiva (VAN VLECK, 1964; WHITE e NICHOLS, 1965; HOQUE e HODGES, 1980). Alguns pesquisadores observaram correlações genéticas positivas, médias ou altas, da produção ao primeiro parto com o número de partos que a vaca teve em sua vida produtiva. HARGROVE et al. (1969) e NORMAN et al. (1996) estimaram valores que variaram de 0,24 a 0,38 .

MEYER (1984) encontrou correlações genéticas entre produções de leite, nas três primeiras lactações, que variaram de 0,52 a 0,56; para produção de gordura, esses valores variaram de 0,47 a 0,52. Já ALBUQUERQUE et al.(1996), utilizando também informações das três primeiras lactações de rebanhos da raça Holandesa, na Califórnia e em Nova York, registraram valores que variaram de 0,38 a 0,50 e 0,30 a 0,46 , para produções de leite e gordura, respectivamente.

GARCÍA-CORTÉS et al. (1995), trabalhando

\footnotetext{
1 Pesquisador da Embrapa - Gado de Leite. E.mail: ary@cnpgl.embrapa.br; jvalente@cnpgl.embrapa.br; martinez@cnpgl.embrapa.br dcm075@cnpgl.embrapa.br; nilson@cnpgl.embrapa.br

2 Bolsista do CNPq.

3 Superintendente Técnico da ACGHMG.
} 
com lactações de gado Holandês do norte da Espanha, analisaram as produções de leite, gordura e proteína nas quatro primeiras lactações com um modelo em que se envolveram 12 características em análises multivariadas. Estimaram correlações genéticas entre as produções de leite e gordura da ordem de 0,77 ; 0,$71 ; 0,85 ;$ e 0,73 , respectivamente, para as quatro primeiras lactações e de 0,90, 0,91, 0,91 e 0,83 para produção de leite e proteína.

O uso de outras lactações, além da primeira, na avaliação de vacas e touros tem sido aceito por muitos pesquisadores (MEYER, 1984; TEEPKER e SWALVE, 1988; ALBUQUERQUE et al., 1996; PÖSÖ e MÄNTYSAARI, 1996b). Assume-se, em geral, que os genes que afetam a produção na primeira lactação são os mesmos que influenciam a produção nas lactações seguintes; portanto, a primeira, a segunda e a terceira lactações seriam uma mesma característica. Se somente dados de vacas que possuem as três primeiras lactações completas fossem utilizados nas análises, as estimativas de parâmetros genéticos ficariam livres de vícios, devido aos efeitos de seleção de vacas nos rebanhos (MEYER e THOMPSON, 1984).

Estimativas de parâmetros genéticos para primeiras lactações e lactações posteriores, separadamente, foram registradas por muitos autores, para diversas populações bovinas. As herdabilidades para produção de leite na primeira lactação foram estimadas entre 0,23 a 0,41 e para produção de gordura, entre 0,22 a 0,40 . Na segunda lactação, essas estimativas variaram entre 0,19 e 0,34 , para produção de leite, e 0,17 e 0,33 para gordura, e na terceira lactação, 0,24 e 0,32 para leite e 0,15 e 0,43 para gordura (TONG et al., 1979; POWELL et al.,1981; MEYER, 1984; ALBUQUERQUE et al., 1996; PÖSÖ e MÄNTYSAARI, 1996a; PÖSÖ e MÄNTYSAARI, 1996b).

O objetivo deste trabalho foi estimar os componentes de variâncias e co-variâncias, para cada uma das três primeiras lactações, para produção de leite e gordura, e os parâmetros genéticos para essas características na população de gado Holandês PO no Estado de Minas Gerais.

\section{Material e Métodos}

Os dados utilizados nas análises foram obtidos do arquivo do controle leiteiro e registro genealógico da Associação dos Criadores de Gado Holandês de Minas Gerais (ACGH - MG) e referem-se às lactações de animais puros de origem (PO) da raça. Eliminaram-se todas as lactações encerradas com duração inferior a 240 dias, por terem encerramentos anormais. Da mesma forma, foram eliminadas das análises as vacas cujo primeiro parto ocorreu com menos de 20 meses. As classes de rebanho-ano de parto com menos de cinco vacas paridas foram excluídas para evitar possíveis efeitos de controle leiteiro seletivo. Foram eliminadas do arquivo de dados 180 vacas que não tinham a segunda lactação por algum motivo, mas tiveram a primeira e a terceira, o que representou $1,9 \%$ das vacas. Assim, permaneceram no conjunto de dados 9527 lactações de primeiro a terceiro parto, iniciadas entre 1988 e 1997 , das quais 5488 vacas possuíam a primeira lactação, 2656 a primeira e a segunda e somente 1281 vacas possuíam as três lactações.

Foram formados dois conjuntos de dados: o primeiro (conjunto I) constituído de somente vacas primíparas e o segundo (conjunto II), de vacas que possuíam as três lactações. O primeiro conjunto foi usado para a obtenção das avaliações genéticas de vacas e touros para leite e gordura. Numa análise bivariada (leite e gordura), estimaram-se parâmetros genéticos adotando-se a metodologia de máxima verossimilhança restrita (REML), com modelo animal, usando o algoritmo desenvolvido por BOLDMAN et al. (1995) para características múltiplas.

$\mathrm{O}$ modelo proposto foi: $\mathbf{y}=\mathbf{H h}+\mathbf{Z u}+\boldsymbol{\varepsilon}$, em que y é um vetor de observações para as produções de leite e gordura em 305 dias; $\mathbf{H}$, a matriz de incidência dos efeitos fixos (ano e estação) e idade ao parto, como covariável (efeitos linear e quadrático); h, um vetor de parâmetros desconhecidos representando os efeitos fixos; e $\mathbf{Z}$, a matriz de incidência dos efeitos aleatórios $\mathbf{u} \sim\left(0, A \sigma_{\mathrm{a}}{ }^{2}\right)$, sendo $\mathbf{u}$ o vetor de efeitos aleatórios, que incluiu os valores genéticos dos animais; $\boldsymbol{\varepsilon} \sim\left(0, \mathrm{I} \sigma_{\mathrm{e}}{ }^{2}\right)$ o vetor dos erros aleatórios. As estações do ano foram consideradas como seca (abril a setembro) e águas (outubro a março).

Foram estimados os valores genéticos de cada vaca e obtiveram-se as PTAs (Capacidade de transmissão prevista), que é a metade do valor genético do animal. As médias das PTAs para o ano de nascimento das vacas primíparas forneceram a tendência genética ocorrida nos rebanhos de PO em Minas Gerais no período em estudo.

No conjunto 2, as produções de leite e gordura até 305 dias, na primeira, segunda e terceira lactações, foram consideradas características diferentes e as análises foram feitas usando a mesma metodologia 
Rev. bras. zootec.

indicada para o conjunto I (REML), em um modelo animal para características múltiplas, contendo os mesmos efeitos do modelo usado para o conjunto I.

Análises univariadas preliminares foram realizadas para cada característica separadamente, empregando-se o mesmo modelo e processo de avaliação das características múltiplas, com o objetivo de obter os valores iniciais dos componentes de variância para o início do processo iterativo de multicaracterísticas; com isto, reduziu-se o tempo de processamento computacional. As características foram analisadas duas a duas.

\section{Resultados e Discussão}

As médias para produção de leite e gordura, até 305 dias de lactação, foram $5870 \pm 1662 \mathrm{~kg}$ e $199 \pm$ $55 \mathrm{~kg}$, respectivamente, para o conjunto I. Para o conjunto II, essas médias, na mesma ordem, foram $5521 \pm 1523 \mathrm{~kg}$ e $187 \pm 50 \mathrm{~kg}$, na primeira lactação; $6421 \pm 1789 \mathrm{~kg}$ e $215 \pm 58 \mathrm{~kg}$, na segunda lactação; e $7045 \pm 1903 \mathrm{~kg}$ e $231 \pm 60 \mathrm{~kg}$, na terceira lactação. As médias de idade ao parto foram para a primeira lactação de $896 \pm 147$ dias (conjunto I) e $888 \pm 128$ dias (conjunto II), e para a segunda lactação de 1319 \pm 153 dias e para a terceira $1763 \pm 189$ dias.

As estimativas das (co)variâncias, das correlações genéticas, fenotípicas e de ambiente, e das herdabilidades para produções de leite e gordura na primeira lactação, obtidas com o conjunto I, são apresentadas na Tabela 1. As estimativas de herdabilidades para produções de leite e gordura na primeira lactação foram de $0,28 \pm 0,04$ e $0,20 \pm 0,03$, respectivamente. As estimativas para leite estão dentro dos limites observados na literatura e a estimativa para gordura, abaixo. Esses limites foram de 0,23 a 0,41 para produção de leite e de 0,22 a 0,40 para a produção de gordura (TONG et al., 1979; POWELL et al., 1981; MEYER, 1984; ALBUQUERQUE et al., 1996; PÖSÖ e MÄNTYSAARI, 1996a; PÖSÖ e MÄNTYSAARI, 1996b). No Brasil, COSTA et al. (1999), MACHADO et al. (1999), RORATO et al. (1999) e TORRES et al. (1999) observaram herdabilidades para produção de leite entre 0,22 a 0,49 .

Por outro lado, TONG et al. (1979) e GARCÍACORTÉS et al. (1995), utilizando informações sobre gado Holandês na primeira lactação, estimaram herdabilidades para leite menores do que as deste estudo, sendo os valores obtidos de 0,23 a 0,26 .
A correlação genética entre a produção de leite e gordura na primeira lactação, baseando-se no conjunto I, foi 0,95 (Tabela 1). Esse valor indica que a seleção, para aumentar o volume de leite na primeira lactação, também melhora a produção de gordura. As correlações de ambiente e fenotípica foram 0,87 e 0,88 , respectivamente. Correlação genética entre as produções de leite e gordura na primeira lactação também foram obtidas por GARCÍA-CORTÉS et al. (1995), que estimaram em 0,88 a correlação genética e em 0,77 a de ambiente. TEEPKER e SWALVE (1988) obtiveram 0,77 para correlação genética e 0,54 para a fenotípica, sendo esses valores menores que os obtidos neste estudo.

As estimativas dos componentes de variância e co-variância e correlações genéticas, fenotípicas e de ambiente e herdabilidades para produções de leite e gordura na primeira, segunda e terceira lactações (conjunto II), obtidas em análises multivariadas das características duas a duas, são encontradas na Tabela 2. Tanto para a produção de leite como para a produção de gordura, houve aumento da variância de ambiente nas lactações posteriores à primeira. Isso pode ser causado por fatores que não influenciam a primeira lactação, mas somente as outras, como o período seco anterior, período de serviço, entre outros (VALENTE et al., 1995; TEIXEIRA et al., 1996).

Tabela 1 - Estimativas das variâncias $\left(\sigma^{2}\right)$, co-variâncias $(\sigma)$ e correlações $(r)$ genéticas $(g)$, fenotípicas $(p)$ e de ambiente (e) e herdabilidades $\left(h^{2}\right)$ para produções de leite (l) e gordura (go), para o conjunto com somente primeiras lactações (Conjunto I)

Table 1 - Estimates of genetic ( $g$ ), phenotypic $(p)$ and environmental (e) variances $\left(\sigma^{2}\right)$, covariances $(\sigma)$, and correlations $(r)$ and heritabilities $\left(h^{2}\right)$ for milk $(l)$ and fat (go) yields for the set of datas with only first lactations (Set I)

\begin{tabular}{lcc}
\hline & $\begin{array}{c}\text { Leite }\left(\mathrm{kg}^{2} / 1000\right) \\
\text { Milk }\left(\mathrm{kg}^{2} / 1000\right)\end{array}$ & $\begin{array}{c}\text { Gordura }\left(\mathrm{kg}^{2}\right) \\
\text { Fat }\left(\mathrm{kg}^{2}\right)\end{array}$ \\
\hline$\sigma_{\mathrm{g}}^{2}$ & 343 & 275 \\
$\sigma_{\mathrm{p}_{2}}$ & 1216 & $1356 \mathrm{a}$ \\
$\sigma_{\mathrm{g}}^{2}$ & 873 & 1081 \\
$\mathrm{~h}^{2}$ & $0,28 \pm 0,04$ & $0,20 \pm 0,03$ \\
$\sigma_{\mathrm{gl}, \mathrm{go}}$ & 9,03 & \\
$\sigma_{\mathrm{pl}, \mathrm{go}}$ & 35,77 & \\
$\sigma_{\mathrm{el}, \mathrm{go}}$ & & \\
$\mathrm{r}_{\mathrm{gl}, \mathrm{go}}$ & & 0,95 \\
$\mathrm{r}_{\mathrm{pl}, \mathrm{go}}$ & 0,88 \\
$\mathrm{r}_{\mathrm{e} 1, \mathrm{go}}$ & 0,87 \\
* Os erros-padrão das estimativas das correlações variaram de 0,08 \\
a 0,29. \\
* The standard errors of estimates of correlations ranged from .08 to .29.
\end{tabular}


As estimativas de herdabilidade para produção de leite foram $0,16 \pm 0,09,0,17 \pm 0,11$ e $0,16 \pm 0,10$, para a primeira, segunda e terceira lactações, respectivamente, e para a produção de gordura, de 0,09 $\pm 0,09$, $0,20 \pm 0,11$ e $0,10 \pm 0,16$ (Tabela 2). Essas estimativas foram menores do que aquelas citadas na literatura, com exceção das obtidas por TONG et al. (1979), que obtiveram 0,17 para leite e 0,15 para gordura.

Houve aumento da estimativa de herdabilidade da primeira para a segunda lactação e decréscimo da segunda para a terceira para produção de gordura, no entanto, isto não ocorreu para a produção de leite.

Tabela 2 - Estimativas das variâncias $\left(\sigma^{2}\right)$, co-variâncias $(\sigma)$ e correlações $(r)$ genéticas $(g)$, fenotípica $(p)$ e de ambiente $(e)$ e herdabilidades $\left(h^{2}\right)$ para produção de leite e gordura nas três primeiras lactações (Conjunto II)

Table 2 - Estimates of genetic $(g)$, phenotypic ( $p$ ) and environmental (e) variances $\left(\sigma^{2}\right)$, covariances $(\sigma)$, and correlations $(r)$ and heritabilities $\left(h^{2}\right)$ for milk and fat yields in the three first lactations (Set II)

\begin{tabular}{|c|c|c|}
\hline & $\begin{array}{c}\text { Leite }\left(\mathrm{kg}^{2} / 1000\right) \\
\text { Milk }\left(\mathrm{kg}^{2} / 1000\right)\end{array}$ & $\begin{array}{c}\text { Gordura }\left(\mathrm{kg}^{2}\right) \\
\text { Fat }\left(\mathrm{kg}^{2}\right) \\
\end{array}$ \\
\hline$\overline{\sigma g^{2}}$ & 159 & 108 \\
\hline$\sigma g_{2}^{2}$ & 262 & 352 \\
\hline$\sigma g^{2}$ & 288 & 199 \\
\hline$\sigma \mathrm{p}^{2}{ }_{1}^{3}$ & 999 & 1149 \\
\hline$\sigma \mathrm{p}^{2}{ }_{2}^{1}$ & 1487 & 1735 \\
\hline$\sigma \mathrm{p}_{3}^{2}$ & 1850 & 2069 \\
\hline$\sigma \mathrm{e}^{2}$ & 839 & 1040 \\
\hline$\sigma \mathrm{e}^{2}{ }_{2}$ & 1225 & 1382 \\
\hline$\sigma \mathrm{e}^{2^{2}}$ & 1561 & 1869 \\
\hline$\sigma_{\mathrm{g} 1,2}$ & 179 & 152 \\
\hline$\sigma_{\mathrm{g} 1,3}^{\mathrm{g} 1,2}$ & 174 & 147 \\
\hline$\sigma_{\mathrm{g} 2,3}$ & 240 & 72 \\
\hline$\sigma_{\mathrm{p} 1,2}$ & 629 & 688 \\
\hline$\sigma_{\mathrm{p} 1,3}$ & 568 & 552 \\
\hline$\sigma_{\mathrm{p} 2,3}$ & 750 & 807 \\
\hline$\sigma_{\mathrm{e} 1,2}^{\mathrm{p} 2,3}$ & 450 & 535 \\
\hline$\sigma_{\mathrm{e} 1,3}$ & 394 & 404 \\
\hline$\sigma_{\mathrm{e} 2,3}$ & 510 & 734 \\
\hline$h^{2,3}$ & $0,16 \pm 0,09$ & $0,09 \pm 0,09$ \\
\hline $\mathrm{h}^{2}$ & $0,17 \pm 0,11$ & $0,20 \pm 0,11$ \\
\hline $\mathrm{h}_{3}^{2}$ & $0,16 \pm 0,10$ & $0,10 \pm 0,16$ \\
\hline $\operatorname{rg}_{1,2} *$ & 0,87 & 0,86 \\
\hline $\mathrm{rg}_{1,3}$ & 1,00 & 1,00 \\
\hline $\mathrm{rg}_{2,3}$ & 0,82 & 1,00 \\
\hline $\mathrm{rp}_{1,2}$ & 0,51 & 0,50 \\
\hline $\operatorname{rp}_{1,3}$ & 0,44 & 0,36 \\
\hline $\mathrm{rp}_{2,3}$ & 0,44 & 0,51 \\
\hline$r e_{1,2}$ & 0,44 & 0,44 \\
\hline $\mathrm{re}_{1,3}^{1,2}$ & 0,33 & 0,30 \\
\hline $\mathrm{re}_{2,3}$ & 0,37 & 0,44 \\
\hline
\end{tabular}

TONG et al.(1979), POWELL et al. (1981), MEYER (1984) e ALBUQUERQUE et al. (1996) concluíram que as herdabilidades da produção de leite e gordura, na primeira lactação, foram mais altas do que nas outras lactações; entretanto, para outros autores, as herdabilidades na primeira e terceira lactações foram mais altas do que na segunda (TEEPKER e SWALVE, 1988; PÖSÖ e MÄNTYSAARI, 1996a; PÖSÖ e MÄNTYSAARI, 1996b).

As correlações genéticas entre as três primeiras lactações foram maiores que 0,82 (Tabela 2). Algumas correlações foram iguais à unidade, sugerindo que as características estão sob os efeitos dos mesmos tipo de genes. Assim, touros e vacas podem ser selecionados usando somente a primeira lactação e, com isso, aumentar o ganho genético por ano.

Nos trabalhos publicados por TONG et al. (1979), POWELL et al. (1981), MEYER (1984) TEEPKER e SWALVE (1988) e ALBUQUERQUE et al. (1996), as correlações da produções de leite e gordura nas três primeiras lactações foram maiores que 0,76 , sendo as correlações entre a segunda e terceira lactações acima de 0,89 . Outros autores encontraram correlações entre as três lactações mais baixas que os valores anteriores (em torno de 0,50), tanto para produção de leite, quanto para gordura (GARCÍACORTÉS et al. 1995; PÖSÖ e MÄNTYSAARI, 1996a; PÖSÖ e MÄNTYSAARI, 1996b).

\section{Conclusões}

As herdabilidades obtidas foram de medianas a baixas, indicando ser possível ganhos genéticos pela seleção e as correlações genéticas entre as produções nas três lactações foram altas. Assim, as avaliações genéticas de vacas e touros podem ser realizadas utilizando-se somente a primeira lactação de cada vaca. Da mesma forma, selecionando-se para produção de leite, está selecionando também para a produção de gordura, devido à alta correlação entre essas características.

\section{Referências Bibliográficas}

ALBUQUERQUE, L.G., KEOWN, J.F., VANVLECK, L.D. 1996. Genetic parameters of milk, fat and protein yields in the first three lactations, using an animal model and restricted maximum likelihood. Rev. Bras. Genet., 19(1):79-86.

BOLDMAN, K.G., KRIESE, L.A, VAN VLECK, L.D. et al. 1995. A manual for use of MTDFREML: A set of programs to obtain estimates of variances and covariances. Lincoln: Department of Agriculture/ Agricultural Research Service. 120p. 
Rev. bras. zootec.

COSTA, C.N. 1999. An investigation into heterogeneity of variance for milk and fat yields of Holstein cows in Brasilian herd environments. Genetic and Molecular Biology, 22(3):375-381.

GARCÍA-CORTÉS, L.A., MORENO, L., VARONA, L. et al. 1995. (Co) variance component estimation of yield traits between different lactations using animal model. Livest. Prod. Sci., 43(2):111-117.

HARGROVE, G.L., SALAZAR, J.J., LEGATES, J.E. 1969. Relationship among first lactation and lifetime measurements in a dairy population. J. Dairy Sci., 52(5):651-656.

HOQUE, M., HODGES, J. 1980. Genetic and phenotypic parameters of lifetime production traits in Holstein cows. J. Dairy Sci., 63(11):1900-1910.

MACHADO, S.G., FREITAS, M.A.R., GADINI, C.H. 1999. Genetic parameters of test day milk yields of Holstein cows. Genetic and Molecular Biology, 22(3):383-386.

MEYER, K. 1984. Estimates of genetic parameters for milk and fat yield for the first three lactations in British friesian cows. Anim. Prod., 38(3):313-322.

MEYER, K., THOMPSON, R. 1984. Bias in variance and covariance component estimators due to selection on a correlated trait. J. Anim. Breed. Genetics, 101(1):33-50.

NORMAN, H.D., POWELL, R.L., WRIGHT, J.R. et al. 1996. Phenotypic relationship of yield and type scores from first lactation with herd life and profitability. J. Dairy Sci., 79(4):689-701.

PÖSÖ, J., MÄNTYSAARI, E.A. 1996a. Genetic relationships between reproductive disorders, operational days open and milk yield. Livest. Prod. Sci., 46(1):41-48.

PÖSÖ, J., MÄNTYSAARI, E.A. 1996b. Relationships between clinical mastitis, somatic cell score, and production for the first three lactations of Finish Ayrshire. J. Dairy Sci., 72(7):1284-1291.

POWELL, R.L., NORMAN, H.D., ELLIOT, R.M. 1981. Different lactations for estimating genetic merit of dairy cows. J. Dairy Sci., 64(2):321-330.
RORATO, P.R.N., VERNEQUE, R.S., MARTINEZ, M.L. et al 1999. Interação genótipo-ambiente para a produção de leite em rebanhos da raça Holandesa no Brasil (I) Modelo de touro. Ciência Rural, 29(4):717-720.

TEEPKER, G., SWALVE, H.H. 1988. Estimation of genetic parameters for milk production in the first three lactations. Livest. Prod. Sci., 20(3):193-202.

TEIXEIRA, N.M., VALENTE, J., VERNEQUE, R.S. et al. Fatores de ajustamento da produção de leite para período de serviço e período seco na raça Holandesa. In: REUNIÃO ANUAL DA SOCIEDADE BRASILEIRA DEZOOTECNIA, 33, 1996, Fortaleza. Anais...Fortaleza: SBZ, 1996. p.54-56.

TONG, A.K.W., KENNEDY, B.W., MOXLEY, J.E. 1979. Heritabilities and genetic correlations for the first three lactations from records subject to culling. J. Dairy Sci., 62(11):1789-1790.

TORRES, R.A., BERGMAN, J.A.G., COSTA, C.N. et al. 1999. Ajustamento para heterogeneidade de variância para a produção de leite entre rebanhos da raça Holandesa no Brasil. R. Bras. Zootec, 28(2):295-303.

VALENTE, J., TEIXEIRA, N.M., VERNEQUE, R.S. et al. Efeitos dos períodos de serviço anterior, período seco anterior e período de serviço corrente sobre a produção de leite. In: REUNIÃO ANUAL DA SOCIEDADE BRASILEIRA DE ZOOTECNIA, 32, 1995, Brasília. Anais...Brasília: SBZ, 1995. p.686-688.

VAN VLECK, L.D. 1964. First lactation performance and herd life. J. Dairy Sci., 47(9):1000-1003.

WHITE, J.M., NICHOLS, J.R. 1965. Relationships between first lactation, later performance, and lenght of herd life in Holstein Friesian cattle. J. Dairy Sci., 48(4):468-474.
Recebido em: Aceito em: 